\title{
COM O PENSAMENTO DO CORAÇÃO, ENTRELAÇANDO DOCÊNCIA E FORMAÇÃO ESTÉTICA
}

\author{
WITH THE THOUGHT OF THE HEART, INTERTWINING TEACHING AND \\ AESTHETIC FORMATION

\section{CON EL PENSAMIENTO DEL CORAZÓN, ENTRELAZANDO DOCENCIA Y FORMACIÓN ESTÉTICA}

\author{
OSTETTO, Luciana Esmeralda \\ lucianaostetto@id.uff.br \\ UFF - Universidade Federal Fluminense
}

\begin{abstract}
RESUMO Este artigo compartilha questões e caminhos de investigação trilhados por um grupo de pesquisa que estuda formação estética docente, arte e infância e assume os aportes teórico-metodológicos das abordagens (auto)biográficas como principais referências. Coloca em discussão concepções de estética, trazendo, para o campo da Educação, elementos que, tradicionalmente, localizam-se no âmbito da Arte e da Filosofia. Em diálogo com o analista James Hillman, para quem a estética diz respeito à necessidade vital de reconhecer a anima mundi, este texto dá visibilidade ao coração como órgão da percepção e lugar da imaginação. Tais ideias, retomadas da tradição filosófica fiorentina e defendidas pelo analista, ajudam a pensar que a formação estética envolve a mobilização do pensamento que passa pelo coração, e, na formação de professores, pode ser potencializada nos espaços para a escrita de si, fertilizando a (re)animação da vida, dentro e fora da docência: aisthesis.
\end{abstract}

Palavras-chave: Arte. Educação Infantil. Formação estética docente. James Hillman. Pesquisa (auto) biográfica.

\begin{abstract}
This paper shares investigation issues and paths pursued by a research group that studies aesthetic in teaching education, art and childhood and assumes the theoretical and methodological contributions of (auto)biographical approaches as main references. It puts into discussion concepts of aesthetics, bringing to the field of Education elements that traditionally are located within the scope of Art and Philosophy. In dialogue with the analyst James Hillman, for whom aesthetics refers to the vital need to recognize the anima mundi, this text gives visibility to the heart as an organ of perception and place of imagination. Such ideas, taken from the philosophical tradition of Fiorentina and defended by the analyst, help to think that aesthetic education involves the mobilization of thinking that passes through the heart, and, during the education of teachers can be enhanced in the spaces for the writing of oneself, fertilizing the (re)animation of life, inside and outside of teaching: aisthesis.
\end{abstract}

Keywords: Aesthetic teacher education. Art. (Auto)biographical research. Early Childhood Education. James Hillman. 
RESUMEN El presente artículo comparte cuestiones y caminos de investigación trazados por un grupo de investigación que estudia formación estética docente, arte e infancia y asume los aportes teórico-metodológicos de los abordajes (auto)biográficos como principales referencias. Plantea la discusión de concepciones de estética trayendo, para el campo de la Educación, elementos que tradicionalmente se ubican en el ámbito del Arte y de la Filosofía. En diálogo con el analista James Hillman, para quien la estética se refiere a la necesidad vital de reconocer la anima mundi, este texto destaca al corazón como órgano de la percepción y lugar de la imaginación. Tales ideas, retomadas de la tradición fiorentina y defendidas por el analista, ayudan a pensar que la formación estética incluye la movilización del pensamiento que pasa por el corazón, y, en la formación de profesores, puede ser potencializada en los espacios para la escritura de sí, fertilizando la (re)animación de la vida, dentro y fuera de la docencia: aisthesis.

Palabras clave: Arte. Educación infantil. Formación estética docente. Investigación (auto)biográfica. James Hillman.

\section{FORMAÇÃO DOCENTE, INFÂNCIA E ARTE: NARRATIVAS EM PESQUISA}

Em diálogo com a arte, entrelaçando formação docente, infâncias, cotidiano educativo e linguagens, nosso grupo de pesquisa (Círculo de Estudo e Pesquisa Formação de Professores, Infância e Arte - FIAR ${ }^{1}$ ) investiga processos formativos e práticas pedagógicas no âmbito da Educação Básica, especialmente da Educação Infantil. Compreendendo a necessidade de olhar para as infâncias além dos limites institucionais, também investiga especificidades de bebês e de crianças pequenas em diferentes contextos.

Os temas das reuniões e dos estudos, os tempos de orientação e as formas de pensar a produção acadêmica configuram uma dinâmica de trabalho circular e colaborativa, por meio da qual vamos tecendo a identidade de um grupo que é constituído, além das professoras orientadoras, por estudantes de Graduação (orientandos de monografia, bolsistas de Iniciação Científica e de Extensão), orientandos de Mestrado e Doutorado e professoras da Educação Básica. Palavraschave, tais como: educação estética, arte e infância, narrativas autobiográficas, formação de professores, Educação Infantil, linguagem e cotidiano de bebês, educação em museus, formação cultural de professores, formação estética docente,

\footnotetext{
1 www.fiar.sites.uff.br
} 
memorial de formação estética, revelam temas que estão sendo enfrentados pelo grupo, situando-se o principal referencial teórico-metodológico das pesquisas realizadas no campo das abordagens narrativas e (auto)biográficas (JOSSO, 2004; DELORY-MOMBERGER, 2006, 2008; PASSEGGI, 2008; NÓVOA; FINGER, 2010, entre outros).

Se, como pondera o analista James Hillman (2010, p. 47): "A beleza é uma necessidade epistemológica, é o modo como os Deuses tocam nossos sentidos, alcançam o coração e nos atraem para a vida. A beleza também é uma necessidade ontológica, fundamentando a particularidade sensorial do mundo", observamos que o mergulho nas histórias de vida inaugura movimentos de busca de imagens que falam dos processos de constituição das subjetividades e podem revelar a beleza como parteira do ser e da escrita de si. Pesquisar a dimensão estética na formação de professores, seguindo as pistas metodológicas das perspectivas (auto)biográficas, significa perscrutar indícios de tempos, lugares e acontecimentos que marcam possibilidades e limites da experimentação sensível, no encontro com a arte, a natureza e a cultura, corpo inteiro ou sua negação.

O sentido de estética assumido recuperamos da tradição filosófica clássica, da raiz grega aisthesis, "[...] que significa sensação, sensibilidade, percepção pelos sentidos ou conhecimento sensível-sensorial" (HERMANN, 2005, p. 25). Se na perspectiva moderna a primeira definição de estética "[...] aparece em 1750, na obra Aesthetica, e marca seu surgimento como uma disciplina filosófica, ao lado da lógica, da metafísica e da ética” (HERMANN, 2005, p. 25), é oportuno lembrar que não esteve, inicialmente, ligada à arte, mas "nasceu como um discurso sobre o corpo" (EAGLETON, 2010, p. 1).

Em sua formulação original, pelo filósofo alemão Alexander Baumgarten, o termo não se refere primeiramente à arte, mas, como o grego aisthesis, a toda a região da percepção e sensação humanas, em contraste com o domínio mais rarefeito do pensamento conceitual. A distinção que o termo "estética" perfaz inicialmente em meados do século XVIII, não é aquela entre "arte" e "vida", mas entre o material e o imaterial: entre coisas e pensamentos, sensações e ideias; entre o que está ligado a nossa vida como seres criados opondo-se ao que leva uma espécie de existência sombria nos recessos da mente. (EAGLETON, 2010, p. 1). 
Como o mundo atinge nossas sensações e percepções? Sem desconsiderar as marcas históricas dos embates e dos atravessamentos que circunscrevem o conceito de estética, ao trazermos a discussão para o campo da formação docente, deslocamo-nos dos usos modernos para compreender a formação estética em íntima relação com os processos de percepção, de imaginação, de interpretação, no mundo e com o mundo, por meio dos quais a sensibilidade é alargada. Oportunamente, ao discutir sobre educação estética, Dante Galeffi (2007) reafirma caminhos que vimos tecendo, ao ponderar que o estético transcende qualquer conteúdo da cultura artística. Diz o referido autor:

\footnotetext{
Educação estética não é apenas aprender a ouvir uma música, a cantar uma cantiga, a observar uma pintura, a dançar, a fazer teatro, a ler literatura. [...] o estético é aquilo que cada um é em sua superfície existencial, porque o importante é o como são desafiadas e afiadas as cordas do tempo e da transformação inevitável. (GALEFFI, 2007, p. 104).
}

Ao longo de nossas vidas, pelo pertencimento a diferentes grupos de convívio, como a família, a escola, as associações, os clubes e as igrejas, compartilhando com eles experiências, hábitos e valores, também atravessados por referências culturais mais amplas, veiculadas pelos meios de comunicação, vamos sendo marcados, aprendendo a significar o mundo ao redor, no compartilhar relações, experiências e contextos diversos; vamos nos apropriando de modos de ser, de pensar e de sentir. Por esses caminhos, vamos nos formando esteticamente, constituindo "[...] um repertório individual, um conjunto de valores, conceitos, ideias, sentimentos, emoções que vão tecendo uma rede de significações para si" (MARTINS; PICOSQUE; GUERRA, 1998, p. 21); um repertório que, de certa forma, orienta a atribuição de significados e sentidos ao vivido, abrindo ou fechando as possibilidades de inventarmos formas, cores, sons, gestos, histórias e de reinventarmos a própria existência.

Nesse quadro de referências, são questões fundantes das pesquisas do FIAR: Onde acontece a formação estética do professor? Como sua história de vida, dentro e fora da escola, desenhou percursos formativos pela via estética? Qual a contribuição da arte para a formação dos professores de Educação Infantil? A arte está presente em seus processos formativos - de que maneira, em que tempos, em 
que espaços, com quem? Adentrar a investigação desse campo, seguindo pistas a partir dos questionamentos formulados implica, inicialmente, colocar em pauta os processos vividos pelo próprio pesquisador. Por isso, o memorial de formação é assumido como princípio da vida desse grupo. Como um dispositivo de geração de dados biográficos, apresenta-se como espaço privilegiado de reflexividade biográfica para aquele que está na jornada de investigação: com foco nos percursos de suas experiências estéticas, todos os participantes produzem seu memorial, o qual se torna parte do trabalho acadêmico em desenvolvimento (relatório de extensão ou iniciação científica, monografia, dissertação, tese).

O memorial autobiográfico (PASSEGGI, 2008), como documento em que são narrados processos de formação, exercício de articular acontecimentos que se relacionam às experiências de formação, dentro e fora da escola, na atuação profissional e na vida como um todo, amplifica dimensões da existência implicadas no processo de se fazer educador e pesquisador. Como exercício autobiográfico, o memorial é ato, movimento, tempo e espaço que apoia o nascimento ou, utilizando a bela imagem esculpida pela pesquisadora, é "aparar a si mesmo com suas próprias mãos" (PASSEGGI, 2008, p. 27). Citamos a autora:

\footnotetext{
Auto-bio-grafar é aparar a si mesmo com suas próprias mãos. Aparar é aqui utilizado em suas múltiplas acepções: segurar; aperfeiçoar; resistir ao sofrimento, cortar o que é excessivo e, particularmente, como se diz no Nordeste do Brasil, aparar é ajudar a nascer. Esse verbo, rico de significado permite operar a síntese do sentido de bio-grafar-se, aqui entendido, ao mesmo tempo, como a ação de cuidar de si e de renascer de outra maneira pela mediação da escrita. (PASSEGGI, 2008, p. 27).
}

Na multiplicidade de formas e de conteúdos das escritas de si, o foco da tessitura do memorial, no FIAR, recai sobre os processos de formação estética. Considerado essencial no percurso de fazer-se pesquisador, temos chamado de memorial de formação estética a narrativa de si, produzida na busca de memórias sobre as marcas do encontro de cada um com a arte, presenças ou silenciamentos; lembranças e reflexões sobre os modos de contato com a cultura e a natureza, delineando percursos de experiências estéticas - limites e possibilidades da educação das sensibilidades. 
Temos observado que, na produção do memorial de formação estética, o contato com diferentes materialidades e linguagens expressivas (do lápis de cor e recorte-colagem, à música e à dança) permite ao narrador (no caso, não só o pesquisador, mas também os participantes das pesquisas em que utilizamos esse dispositivo) confrontar vestígios que se anunciam nas imagens rememoradas e nas expressões criadas, muitas vezes provocando o deslocamento da reflexão, ampliando olhares e amplificando sentidos em suas narrativas. Se o fazer à mão (compreendido como fazer de corpo inteiro), convoca pensamento, sentimento, intuição e sensação, no contexto da produção de narrativas autobiográficas franqueia passagem para que o narrador-professor-pesquisador integre dimensões do sensível e do inteligível: fazer à mão, antes da palavra escrita, contribui para fertilizar a poesia de cada um (OSTETTO, 2016).

Com relação aos traçados teórico-metodológicos de nossas pesquisas, como já indicado, caminhamos em diálogo com as abordagens narrativas e (auto)biográficas, um específico campo de investigação

[...] que se interessa pela maneira com a qual os indivíduos dão uma forma às suas experiências, com a qual eles comunicam as situações e os eventos de suas existências, com a qual eles inscrevem o curso de suas vidas no seu ambiente histórico e social. (DELORY-MOMBERGER, 2008, p. 93).

As histórias de vida, como construções biográficas, podem ser acessadas por meio de atos de memória, que ganham texturas e matizes peculiares na narrativaescrita de si: a biografia é aqui compreendida como "[...] representação construída da existência através das operações da prática de narrar, de relatar, de construir enredos" (DELORY-MOMBERGER, 2008, p. 93).

Nesse contexto, dentre os diferentes dispositivos utilizados para a geração e análise de dados biográficos, temos utilizado os princípios da entrevista narrativa, sistematizada pelo sociólogo alemão Fritz Schütze (nascido em 1944) e (re)apresentada por Jovchelovitch e Bauer (2012).

A entrevista narrativa tem em vista uma situação que encoraje e estimule um entrevistado a contar a história sobre algum acontecimento importante de sua vida e do contexto social. A técnica recebe seu nome da palavra latina narrare, relatar, contar uma história. Em um manuscrito não 
publicado, Schütze (1977) sugeriu uma sistematização dessa técnica. Sua ideia básica é reconstruir acontecimentos sociais a partir da perspectiva dos informantes, tão diretamente quanto possível. (JOVCHELOVITCH; BAUER, 2012, p. 93).

A entrevista narrativa vem sendo utilizada no campo dos estudos (auto)biográficos, pois a forma específica de geração de textos narrativos (quando a escuta e a não interrupção do entrevistador, com perguntas ou pedido de esclarecimentos, são pressupostos decisivos), possibilita a ruptura com situações de entrevistas estruturadas e/ou semiestruturadas, baseadas no esquema perguntasrespostas. Na base da proposta da entrevista narrativa, está a concepção de que "[...] a perspectiva do entrevistado se revela melhor nas histórias onde o informante está usando sua própria linguagem espontânea na narração dos acontecimentos" (JOVCHELOVITCH; BAUER, 2012, p. 95). No caso de nossos interesses de pesquisa, a entrevista faz-se como acontecimento que permite rememorar histórias consideradas pelo entrevistado-narrador determinantes para sua formação, cultural e estética, em diferentes tempos e lugares no percurso de sua vida.

\begin{abstract}
Através da narrativa, as pessoas lembram o que aconteceu, colocam a experiência em uma sequência, encontram possíveis explicações para isso, e jogam com a cadeia de acontecimentos que constroem a vida individual e social. Contar histórias implica estados intencionais que aliviam, ou ao menos tornam familiares, acontecimentos e sentimentos que confrontam a vida cotidiana normal. (JOVCHELOVITCH; BAUER, 2012, p. 91).
\end{abstract}

A proposta do ateliê biográfico de projeto, formulada pela pesquisadora Christine Delory-Momberger (2006), mostra-se também como profícuo caminho para a geração de dados narrativo-biográficos no campo da pesquisa sobre formação estética docente e, assim, tomamo-la como fonte de inspiração para nossas proposições metodológicas. Segundo a referida autora, o ateliê biográfico de projeto é definido como:

[...] um procedimento que inscreve a história de vida em uma dinâmica prospectiva que liga o passado, o presente e o futuro do sujeito e visa fazer emergir o seu projeto pessoal, considerando a dimensão do relato como construção da experiência do sujeito e da história de vida como espaço de mudança aberto ao projeto de si. (DELORY-MOMBERGER, 2006, p. 359). 
Um movimento singular de investigação sobre os percursos pessoais começa quando paramos intencionalmente para pensar, rememorando as experiências que compõem nossa história, quando nos dispomos a refletir sobre nossos processos formativos ao longo da vida. Tal investigação biográfica conduz à iluminação de áreas de nossas vidas que estavam à sombra, convocando-nos a (re)descobrir saberes e fazeres que nos constituem pessoal e profissionalmente, interpelandonos: para onde vou daqui? $O$ movimento intencional de sair em busca, embrenhando-se pelos recônditos da memória, vai iluminando regiões por vezes desbotadas pelo tempo, contribuindo para visibilizar fios de histórias particulares que advêm do passado, entrelaçam-se em fluxos retomados no presente e, na medida em que são revelados, podem desencadear novos projetos de si. A reflexividade biográfica ativa processos de "biografização" (DELORY-MOMBERGER, 2006, p. 369), nos quais, pelo exercício da memória, as marcas do vivido são revisitadas pelo olhar que retorna ao passado na história do presente, oferecendo elementos para a compreensão do percurso e, dessa forma, para a projeção de outros caminhos, afirmando ou redefinindo rotas e tramas. Na dinâmica da reflexividade biográfica, o projeto de si ganha possibilidade de ser lançado em direção ao futuro. Como diz a autora:

[...] o impulso do projeto de si permite advir à perspectiva de uma história que desenha um futuro possível e se concretiza em projetos singulares. Vias se abrem, não porque o passado foi reconhecido como tal e por si mesmo, mas porque a dinâmica prospectiva induziu uma história de si, que não está fechada sobre si, mas que dá lugar ao que virá, deixando emergir potencialidades projetivas. (DELORY-MOMBERGER, 2006, p. 365).

\section{ESPAÇOS FORMATIVOS DA SENSIBILIDADE ESTÉTICA: ONDE?}

Com a intenção de contribuir com o conhecimento e o debate de um campo relativamente novo, relacionado a pesquisas que tematizam a formação estética, a seguir serão apresentados dados parciais da pesquisa interinstitucional em andamento (Espaços de formação docente: memórias e narrativas estéticas), desenvolvida por professoras que atuam em duas universidades públicas do Sudeste, em uma Faculdade de Educação e em uma Escola de Belas Artes, a qual pretende identificar e colocar em diálogo as experiências estéticas nos percursos de 
formação de licenciandos de Pedagogia e de Arte das duas universidades (OSTETTO; BERNARDES, 2016). São objetivos específicos desta investigação: analisar elementos dos caminhos de formação estética trilhados por estudantes de Pedagogia e de Arte, apontados em seus memoriais de formação; problematizar a contribuição da formação escolar e universitária nos percursos biográficos dos licenciandos; identificar, nos registros das histórias de vida fertilizados pela ação do rememorar, tempos e espaços de formação estética, recorrentes e mais significativos; discutir possibilidades investigativo-formativas do ateliê biográfico de projeto.

Os dados aqui apresentados e analisados referem-se à etapa da pesquisa que contou com a participação de vinte e sete estudantes de Pedagogia, com os quais foram realizados dez encontros-ateliês. Inspirados nos elementos do ateliê biográfico de projeto (DELORY-MOMBERGER, 2006), os encontros-ateliês foram desenvolvidos na articulação de quatro movimentos, não lineares ou sequenciais, mas integrativos, indicados a seguir.

- Movimento inicial: ativação das memórias, em busca de localizar o primeiro encontro forte com a arte, compartilhando com o grupo, em narrativa oral produzida.

- Segundo movimento: vivências corporais e produção de atividades plásticopictóricas, pressupondo a imersão nas histórias vividas, aproximando lembranças, sensações, gostos e desgostos, fertilizando indícios dos caminhos por meio dos quais se deu a formação do olhar, das sensibilidades, do estético.

- Terceiro movimento: exercício-esboço de escrita de si, projeto de memorial de formação, chegando mais perto das experiências estéticas constituintes de sua história, com a arte, a cultura, a natureza, produzindo o Diário poético de memórias e de miudezas.

- Movimento síntese: a narrativa de si tecida no memorial de formação estética - projetar-se, considerando que "[...] a linguagem é o espaço onde se fabrica, ao mesmo tempo e indissociavelmente, uma 'história' e o 'sujeito' dessa história" (DELORY-MOMBERGER, 2006, p. 364). 
A partir de uma questão-convite - escavar a memória, localizar o primeiro contato com a arte e, desse ponto, seguir em busca das experiências consideradas mais significativas para o desenvolvimento de sua sensibilidade - , o conteúdo pautado para a rememoração e a reflexão sobre modos, tempos, espaços, movimentos, relações, encontros, desencontros, experiências formadoras da sensibilidade estética de cada um, acompanhou todos os encontros, atravessandoos como figura-fundo que dá referência para distinguir deslocamentos e experimentações.

Os encontros-ateliês, mediados pelos fazeres expressivos propostos (pintura, recorte-colagem, desenho, música, dança, entre outros), abriram espaço para a enunciação das histórias de vida: da experimentação com diferentes materialidades no presente, facilmente os participantes se remetiam ao passado, refletindo sobre possibilidades ou limitações no contato com tais materialidades em seu percurso. Por sua vez, as ações engendradas pelos materiais expressivos disponibilizados (seja manipulação, transformação, movimentação) provocam, também, a ampliação das sensibilidades. Como apontado por outros pesquisadores (FORMENTI, 1996; OSTETTO; BERNARDES, 2015; OSTETTO, 2016), o contato com diferentes linguagens e materialidades expressivas é deveras apropriado e instigante para suscitar memórias e narrativas. Provocar a experimentação e a criação, intensificar o movimento de olhar para si, é como abrir espaço para os participantes-narradores articularem compreensivamente dados do vivido, projetando-se na palavra que fora fertilizada desde os atos de memória iniciais, à criação plástico-pictórica ou expressivo-corporal.

Os dados (a)colhidos ao longo dos encontros-ateliês constam de fotografias dos processos vivenciados e produções dos participantes, áudio-gravações de narrativas orais, memorial de formação estética de cada participante e o Diário poético das miudezas, espécie de caderno de memórias das coisas fugidias, coleção de ideias, imagens, fragmentos do viver, recolhidos do chão do dia a dia, para serem ressignificadas. Tal diário foi inspirado no livro 'Tratado geral das grandezas do ínfimo' (BARROS, 2009), especialmente no poema Miudezas, que transcrevo a seguir. 
Atos de Pesquisa em Educação - ISSN 1809-0354

Blumenau, v.14, n.1, p.57-76 jan./abr. 2019

DOI: http://dx.doi.org/10.7867/1809-0354.2019v14n1p57-76

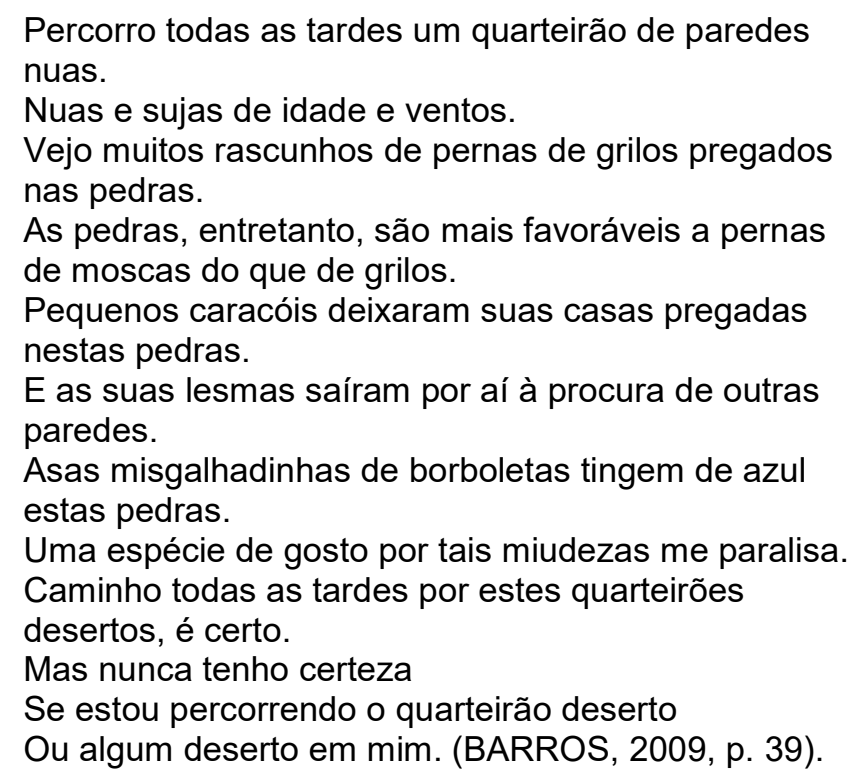

Notas de campo da pesquisadora e da bolsista de iniciação científica também compõem o material da pesquisa. No que concerne às questões éticas, cabe esclarecer que todos os participantes assinaram o Termo de Consentimento Livre e Esclarecido.

Para o presente artigo, considerando que a pesquisa está em andamento, serão utilizadas apenas as notas de campo e as narrativas orais dos participantes nos primeiros movimentos dos encontros-ateliês. Dando visibilidade ao movimento da pesquisa, mas sem a intenção de descrever todos os encontros, será traçado, a seguir, um panorama com alguns elementos que compuseram o processo.

Para começar nossos encontros-ateliês, a leitura da narrativa de uma professora de Educação Infantil - 'Meu encontro com Picasso... e comigo' (SILVA, 2005) - compartilha histórias de seu percurso formativo, alegrias e tristezas da experiência escolar, marcadas pelo controle e pela imposição de modelos, até o encontro com as obras de Picasso, considerada um marco para a revisão de sua prática pedagógica (diante da novidade que foi viajar a São Paulo e ficar frente a frente com as obras de Picasso, admirar formas, dimensões, cores, composições). Isso permitiu que vários fios fossem puxados para tecer o curso das rememorações e aquecer as conversas sobre as experiências com a arte, na escola e fora dela. De modo geral, os participantes se identificaram com a narrativa da professora de Educação Infantil que conta suas desventuras na escola. Colorir desenhos prontos, 
pintura livre em folhas A4, fazer trabalhinhos com tinta guache ou recorte-colagem, ensaiar músicas, dancinhas e teatros para dias festivos foram lembranças recorrentes da infância dos participantes, revelando a escola como um espaço com poucas oportunidades de expansão sensível, tempo marcado pela interdição da experiência criativa, de cerceamento dos sentidos. Na reflexão, ativada pelo compartilhamento de memórias dos participantes em diálogo com a narrativa lida, reconheceram em si a queixa de muitos adultos ("eu não sei desenhar") e ponderaram que o afastamento do desenho (o medo de desenhar, a ideia cristalizada de não saber fazer o certo) foi sendo forjado na escola da infância.

Nesse contexto, como não se lembrar do clássico trabalho de pesquisa da professora Ana Angélica Albano - 'O espaço do desenho: a educação do educador', publicado no início dos anos 1980? Ao discutir a concepção de desenho e seu desenvolvimento na infância, o trabalho assinala um fenômeno corrente à época, e ainda não superado: a perda progressiva do desenho da criança, para a qual contribuem práticas pedagógicas de professores que, por sua vez, também perderam seus desenhos e se queixam: eu não sei desenhar (ALBANO, 2002). A pesquisadora chama atenção para a necessária formação estética do professor, que passa pela disposição de sair em busca de suas linguagens, pelo exercício de autoconhecimento, abertura de sentidos para (re)visões e (re)aprendizagens.

Reaprender a ver, a se espantar com o que vê... [...]. Buscar dentro de si o que tem a dizer e não ter medo, buscando recuperar no seu traço a sua palavra. É um processo de conhecimento, de enfrentamento das imagens internas e da realidade externa. Olhar que olha para dentro e para fora. (ALBANO, 2002, p. 95).

A pesquisa em desenvolvimento, ao produzir dados no encontro com professores em formação, metodologicamente propõe oportunidades para aquele espanto referido por Albano (2002): diante da novidade do mundo, abre canais para (re)conexões outras, alimentando olhares multidirecionados, para dentro e para fora do sujeito aprendente. Assim, por exemplo, as narrativas dos estudantesprofessores em formação participantes da pesquisa demonstravam que as experiências com o desenho foram malsucedidas ao longo da vida escolar. No processo dos ateliês, o contato com o livro 'Picasso em uma só linha' (GALASSI, 
1998) instigou o reencontro com a linguagem do desenho: desenhar em papéis grandes, pequenos, médios, ínfimos, segundo suas escolhas, sem levantar o lápis do papel, provocou descontração, liberação, diversão. As expressões durante os processos atestavam o reencontro essencial, não sem reservas, mas com vontade.

O desenho-diálogo com carvão vegetal sobre suporte de papel pardo anexado na parede deu continuidade às experimentações, em encontros seguintes. Aquela materialidade incomum e estranha aos estudantes foi um potente convite à busca por territórios desconhecidos, que acionavam regiões silenciadas dos fazeres sensíveis. Chamava à criação. Nos diálogos do fazer, marcando o suporte com traços do carvão vegetal, esfumando-o ou recobrindo-o com outras texturas, comentavam sobre as noções escolares e sociais do certo e do errado, do belo e do feio, assinalavam a necessidade de olhar com disposição para o que não se conhece e se colocar em experiência para poder construir (outros) significados. $O$ prazer estava estampado nos jeitos dos corpos, nos risos, na entrega, nas exclamações: Nossa! É muito bom, delicioso!

Exercícios de olhar e de imaginar foram desencadeados pela proposta de fotografar cantos e recantos do campus universitário: sair em busca de detalhes, procurando ver o que não está claramente visível, escavar pelo olhar o que se esconde, tentar um ângulo não usual, distanciando-se do olhar habituado, do caminho já palmilhado no ir e vir cotidianos. As fotografias digitais foram compartilhadas e suscitaram boas conversas sobre olhares, gostos, medos, desejos, que, por sua vez, revelavam histórias de formação, deram a conhecer perspectivas estéticas. As crônicas: 'Vista cansada' (RESENDE, 1992) e 'É preciso olhar a vida com olhos de criança' (MATISSE, 2007) serviram de ponte para o adensamento da reflexão sobre modos de olhar, sobre gostos, hábitos e rotinas que nos impedem de ver além do já conhecido.

No desenrolar dos encontros, experimentando, colocando-se disponíveis para o novo, também os exercícios de memória iam sendo fertilizados. Nesse contexto, foram tecidas as primeiras narrativas sobre o encontro mais antigo, quiçá o primeiro encontro forte, com a arte. Ouvindo as vozes dos participantes, foi curioso perceber que, não raramente, começavam com "foi difícil pensar", "não lembro da arte em minha vida", "acho que não tive muito contato com coisas da arte", "parece que não 
esteve muito presente na minha vida" (Notas de pesquisa, 2017). Os relatos de memória, após a travessia da barreira do esquecimento, contam de dois espaços especialmente: o convívio familiar e a escola.

Quando fazem referência ao espaço familiar, falam do contato com literatura e contos tradicionais; dizem que cantigas, música popular brasileira e ópera eram apreciadas em casa; contam da visita-passeio ao museu da cidade e da ida ao teatro pela primeira vez; lembram-se do convívio íntimo com pinturas em casa, onde avós ou pais eram artistas. Presenciar o trabalho de artesanato da mãe e poder compartilhar seus materiais, explorar o quintal e fazer tinta com as frutas também foram identificados como experiências primeiras com a arte; a Mona Lisa marcou o olhar de quem diariamente se encontrava com a figura, cuja reprodução estava pendurada na parede de casa, ao lado de fotografias familiares, e se perguntava: quem é ela?

No espaço escolar, além das lembranças de experiências pobres, marcadamente na Educação Infantil, onde as reproduções e os trabalhos com os materiais comuns (lápis de cor, giz de cera, tinta guache e papel A4) era a regra, há narrativas, localizadas nos anos finais do Ensino Fundamental e no Ensino Médio, que revelam a importância do encontro com as histórias e imagens de obras de artistas (citam Claude Monet, Portinari e Edvard Munch); o caderno de desenho aparece como material de base, mas falam de participação em canto coral, grupo de dança e saída para visitar museus e ir ao teatro.

Talvez pudéssemos questionar: os elementos trazidos à lembrança configuram encontros com a arte? No entanto, esse ponto não está em discussão. 0 importante é perceber contornos de experiências estéticas (algumas anestésicas, é bem verdade) que se anunciaram nas narrativas - envolvendo olhares, sensações, vozes e movimentos, saberes do corpo, fazer à mão, experimentações. Indicam percursos por meio dos quais o ser da poesia de cada criança, adolescente ou jovem pode se expandir (por vezes contrair). Se, por um lado, as narrativas revelam o limite de experiências poéticas, inventivas, e a escassez de propostas artísticas e culturais na Educação Infantil, a casa aparece como o espaço que oferecia oportunidades de ativar sentidos, experimentando, ouvindo, fazendo, compartilhando 
repertórios simbólicos, valores, conceitos, ideias, sentimentos, emoções (MARTINS; PICOSQUE; GUERRA, 1998).

Importante notar, nas narrativas, que o contexto afetivo marca tempos e espaços de formação estética: "Minha lembrança da arte é da tradição oral, a cantiga que minha vó cantava. Eu fui educada pela sua voz"; "Meu avô me chamava para escutar ópera com ele"; "Olhando o artesanato da minha mãe, conhecia as cores, as formas, e fui gostando"; "Fiz junto com minha mãe um mosaico, de papel picado, sobre a obra de um artista"; "Ir ao museu era um acontecimento, pois estava em família. Não lembro da exposição, só do lugar"; "Fui no museu e vi as estrelas era uma exposição sobre astros do universo. Nunca mais esqueci aquela sensação e hoje ainda sou interessada no assunto" (Notas de pesquisa, 2017). A dimensão estética, como aquilo que conecta (VECCHI, 2013), atravessa a existência, é tecida ao longo da vida com os fios da sensibilidade e da razão, da cognição e do afeto, definindo as possibilidades de construção de sentidos e refinando-os.

Relembrando Galeffi (2007), o estético reside naquilo que cada um é em sua existência, na relação com o mundo, percebendo e sendo percebido, afetando e sendo afetado com o corpo sensível, desfiando e afiando as cordas do tempo, transformando-se. As experiências com a arte, a cultura e a natureza, tramadas na relação com outros significativos, podem afetar todos os sentidos, penetrando a pele, olhos, ouvidos, olfato, paladar, rompendo a indiferença, reafirmando a vida.

\section{RECONHECER A ANIMA MUNDI: VEREDAS DA FORMAÇÃO ESTÉTICA}

\footnotetext{
Ouvir minha vó cantar para mim e minha irmã, era incrível, eu adorava! (Julia, estudante de Pedagogia). [...]

Ao chegar no teatro... que lugar! E o palco? Pura magia! (Patrícia, estudante de Pedagogia).

[...]

Ela ficava na ponta dos pés, jogava as pernas para o alto, girava e fazia incríveis saltos. Uau! Fiquei extasiada! (Monique, estudante de Pedagogia).

(Notas de pesquisa, 2017).
}

Essas expressões são parte do conjunto de narrativas compartilhadas nos encontros-ateliês com estudantes de Pedagogia da pesquisa em andamento. 
Podemos notar, nos enunciados, uma força e uma vivacidade que nos reconduzem à reflexão sobre estética e, por sua vez, ao reencontro com o analista James Hillman, quando localiza a reação estética na respiração entrecortada, na expressão de espanto e surpresa que toma nossos sentidos, quase como um susto que nos paralisa. Diz ele:

Você prende a respiração e fica imóvel. Essa inspirada momentânea, esse pequeno arfar, essa reação de aahhhhh é a resposta estética [...]. Além disso, essa inspirada momentânea é também a própria raiz da palavra estética, em grego aisthesis, que significa sensopercepção. Aisthesis se liga aos aiou e aisthou homéricos, que significam "Eu percebo" e também "Eu ofego, luto por inspirar" e a aisthomai, aisthanomai "Eu inspiro". (HILLMAN, 1993, p. 137).

É interessante perceber os significados envolvidos na palavra estética, além de sensopercepção. Seguindo a tradição grega, o autor escava a raiz do vocábulo para assinalar a relação com a ação de inspirar, absorver ou conduzir o mundo para dentro. E o que é trazer o mundo para dentro? "Primeiro significa aspirar ou inspirar as apresentações literais das coisas profundamente. A transfiguração da matéria acontece pelo maravilhamento" (HILLMAN, 2010, p. 49). Importante destacar que James Hillman trata a resposta estética como um ato cordial, quer dizer, que passa antes pelo coração, em direção oposta às reflexões e às críticas, meramente mentais. Segundo ele:

Na psicologia grega antiga e na psicologia bíblica, o coração era o órgão da sensação, era também o lugar da imaginação. O senso comum (sensus communis) alojava-se dentro e em volta do coração e sua função era apreender imagens. [...]. A função do coração era estética. (HILLMAN, 2010, p. 94).

Julgo importante esclarecer que, ao trazer o coração para a discussão, apoiando-se em diferentes filosofias e, por vezes, amplificando na mitologia, o autor não está se referindo a qualquer tipo de "[...] subjetivismo sentimental, [afeito aos românticos], mas ao coração estético da antiga tradição florentina" (HILLMAN, 2010, p. 94), com o qual se entra imediatamente na imaginação, em que imaginar e sentir são inseparáveis. Contudo, essa compreensão está perdida na contemporaneidade, conforme faz notar o autor: 
[...] em nossa cultura, estamos privados de uma psicologia e de uma filosofia do coração adequadas. Portanto, estamos também privados da imaginação. Nosso coração não apreende que é imaginativamente pensante, pois há muito nos é dito que a mente pensa e o coração sente, e que a imaginação nos desencaminha de ambos. (HILLMAN, 2010, p. 16).

Voltando às narrativas em epígrafe, seja nas expressões utilizadas - incrível, adorava, uau, extasiada, mágico -, seja no tom evidenciado - exclamativo, carregado de admiração, de emoção -, percebemos aquela conexão com o maravilhamento: a pessoa que exclama teve os sentidos afetados, foi tocada pela beleza, atraída para a vida (HILLMAN, 2010). Ao falar de beleza, o autor não está se referindo a qualquer tipo de embelezamento, preocupado com o bom gosto, o simples, o agradável, o bonitinho, mas a uma questão maior, que vai além da arte, de objetos de arte, de história da arte e da teoria da estética; refere-se à manifestação da anima mundi - alma do mundo, "[...] à própria sensibilidade do cosmo, que tem texturas, tons, gostos, que é atraente" (HILLMAN, 2010, p. 45). É a nossa sobrevivência. Reportando-se à mitologia, relembra Afrodite que, como deusa da beleza, é a deusa dos sentidos do mundo. Para adivinhar sua presença, entretanto, é preciso cultivar o tempo que acolhe o pensamento que passa pelo coração: a resposta estética, que é o contrário da passividade, da imobilidade, da indiferença da dormência do coração. Ao modo de uma síntese integradora, canta o compositor brasileiro: "Belezas são coisas acesas por dentro" (MAUTNER apud OSTETTO, 2014, p. 177).

Empenhado em restituir à cultura e à linguagem comum da contemporaneidade a palavra alma, contrastando-a com a noção de psique, termo mais utilizado pelos psicanalistas, no ensaio 'Anima mundi, o retorno da alma ao mundo', James Hillman $(1993,2010)$ postula que, em todas as coisas, há alma e, portanto, tudo tem importância para a vida psíquica. A base de suas formulações teóricas advém do platonismo e do pensamento renascentista de Marsilio Ficino (1433-1499), que falam de um mundo almado, colocando em xeque o sistema recorrente que separa sujeitos animados e objetos inanimados. Entremos no pensamento do autor, imaginemos com ele. 
Atos de Pesquisa em Educação - ISSN 1809-0354

Blumenau, v.14, n.1, p.57-76 jan./abr. 2019

DOI: http://dx.doi.org/10.7867/1809-0354.2019v14n1p57-76

\begin{abstract}
Imaginemos a anima mundi nem acima do mundo que a circunda, como uma emanação divina e remota do espírito, um mundo de poderes, arquétipos e princípios transcendentes às coisas, nem dentro do mundo material como seu princípio de vida unificador panpsíquico. Em vez disso, imaginemos a anima mundi como aquele lampejo de alma especial, aquela imagem seminal que se apresenta por meio de cada coisa em sua forma visível. Então, a anima mundi aponta as possibilidades animadas oferecidas em cada evento como ele é, sua apresentação sensorial como um rosto revelando sua imagem interior - em resumo, sua disponibilidade para a imaginação, sua presença como uma realidade psíquica. (HILLMAN, 1993, p. 14).
\end{abstract}

As coisas falam, exibem uma fisionomia! Em suas cores, texturas, formas, atmosferas e expressões, o mundo e as coisas autoapresentam-se. O quanto podemos ouvi-las, vê-las? A imaginação é o canal para o reconhecimento do mundo almado, "[...] o ato infantil de imaginar o mundo, anima o mundo e o devolve à alma" (HILLMAN, 1993, p. 15). E, por sua vez, a ação de imaginar conecta-se ao órgão da percepção: sentir e imaginar são inseparáveis na reação estética do coração, conforme já assinalado anteriormente, mas a "[...] anima mundi simplesmente não é percebida se o órgão dessa percepção permanece inconsciente ao ser concebido apenas como bomba física ou um reservatório pessoal de sentimentos" (HILLMAN, 1993, p. 18).

Nesse ponto, retomamos a questão da formação estética docente: por meio da rememoração e da escrita de si, no exercício autobiográfico, os professores podem (re)encontrar elementos constituintes de sua sensibilidade, localizar e articular fatos, acontecimentos, relações, experiências; enfim, que os ajudaram a serem quem são, percebendo o mundo e capturando seus sentidos, em texturas, formas, tons, sabores que emanam beleza. No entanto, alimentar olhares e sentidos exige ação, exige que o coração, sede da imaginação e da percepção, segundo a antiga tradição fiorentina, seja tocado. E essa pode ser a tarefa de uma educação que toma para si a articulação de princípios éticos, políticos e estéticos: animar o mundo, reanimar a educação, trazer alma ao cotidiano.

A forma sem anima torna-se formalismo, conformismo, formalidades, fórmulas, formulários - formas sem brilho, sem a presença do corpo, enquanto isso, a beleza é reservada ao gueto das coisas belas: museus, o ministério da cultura, música clássica, a sala escura do presbitério - Afrodite aprisionada. (HILLMAN, 2010, p. 59). 
Falar de si, perscrutar os momentos de beleza, pode constituir-se em uma jornada para libertar Afrodite - a beleza, a imaginação -, ajudando a dar forma à vida com brilho, de corpo inteiro. Eis o elemento de futuro alinhavado no ateliê biográfico de projeto, gestado também com as interpelações narrativas que denunciam perdas e deixam entrever desejos: "Onde foi parar aquele olhar encantado da criança que fui?", "Onde está o tempo para experimentar e brincar?" (Notas de pesquisa, 2017). Na jornada de pesquisar e fazer formação docente, é preciso lembrar: "O pensamento do coração não é algo simplesmente dado, uma reação nativa e espontânea, sempre pronta e sempre lá. Ao contrário, o coração precisa ser provocado, chamado" (HILLMAN, 2010, p. 60).

\section{LUCIANA ESMERALDA OSTETTO}

Professora da Faculdade de Educação na Universidade Federal Fluminense (UFF). Atua na graduação e na pós-graduação - mestrado e doutorado em Educação. Líder do FIAR- Círculo de estudo e pesquisa Formação de Professores, Infância e Arte.

\section{REFERÊNCIAS}

ALBANO, A. A. O espaço do desenho: a educação do educador. 9. ed. São Paulo: Loyola, 2002.

BARROS, M. de. Tratado geral das grandezas do ínfimo. Rio de Janeiro: Record, 2009.

DELORY-MOMBERGER, C. Formação e socialização: os ateliês biográficos de projetos. Educação e Pesquisa, São Paulo, v. 32, n. 2, p. 359-371, ago. 2006.

DELORY-MOMBERGER, C. Biografia e educação: figuras do indivíduo-projeto. Natal-RN: São Paulo-Paulus, 2008.

EAGLETON, T. A ideologia da estética. Rio de Janeiro: Zahar, 2010 (edição digital).

FORMENTI, L. La storia che educa: contesti, metodi, procedure dell'autobiografia educativa. Rivista Adultità, Milano, n. 4, p. 83-100, out. 1996.

GALASSI, S. G. Picasso em uma só linha. Rio de Janeiro: Ediouro, 1998. 
GALEFFI, D. A. Educação estética como atitude sensível transdisciplinar: o aprender a ser o que se é propriamente. Em Aberto, Brasília, v. 21, n. 77, p. 97-111, jun. 2007.

HERMANN, N. Ética e estética: a relação quase esquecida. Porto Alegre: EDIPUCRS, 2005.

HILLMAN, J. Cidade e alma. São Paulo: Studio Nobel, 1993.

HILLMAN, J. O pensamento do coração e a alma do mundo. Campinas, SP: Verus, 2010.

JOSSO, M-C. Experiências de vida e formação. São Paulo: Cortez, 2004.

JOVCHELOVITCH, S.; BAUER, M. W. Entrevista narrativa. In: BAUER, M. W.; GASKELL, G. (Orgs.). Pesquisa qualitativa com texto, imagem e som. Petrópolis, RJ: Vozes, 2012. p. 90-113.

MARTINS, M. C.; PICOSQUE, G.; GUERRA, M. T. T. A língua do mundo: poetizar, fruir e conhecer arte. São Paulo: FTD, 1998.

MATISSE, H. É preciso olhar a vida com olhos de criança. In: MATISSE, H. Escritos e reflexões sobre arte. São Paulo: Cosac Naify, 2007. p. 370-372.

NÓVOA, A.; FINGER, M. (Orgs.). O método (auto) biográfico e a formação. Natal, RN: EDUFRN; São Paulo: Paulus, 2010.

OSTETTO, L. E. Danças circulares na formação de professores: a inteireza de ser na roda. Florianópolis: Letras Contemporâneas, 2014.

OSTETTO, L. E. Fazer à mão para falar de si. In: MONTEIRO, F. de A.;

NACARATO, A. M.; FONTOURA, H. A. da. (Orgs.). Narrativas docentes, memórias e formação. Curitiba: CRV, 2016. p. 143-159.

OSTETTO, L. E.; BERNARDES, R. K. Modos de falar de si: a dimensão estética nas narrativas autobiográficas. Pro-Posições, Campinas, v. 26, n. 1(76), p. 161-178, jan./abr. 2015.

OSTETTO, L. E.; BERNARDES, R. K. Espaços de formação docente: memórias e narrativas estéticas. Projeto de pesquisa. Universidade Federal

Fluminense/Universidade Federal de Minas Gerais, 2016. (Digitado)

PASSEGGI, M. C. Memoriais auto-bio-gráficos: a arte profissional de tecer uma figura pública de si. In: PASSEGGI, M. C.; BARBOSA, T. M. N. (Orgs.). Memórias, memoriais: pesquisa e formação docente. Natal, RN: EDUFRN; São Paulo: Paulus, 2008. p. 27-42. 
Atos de Pesquisa em Educação - ISSN 1809-0354

Blumenau, v.14, n.1, p.57-76 jan./abr. 2019

DOI: http://dx.doi.org/10.7867/1809-0354.2019v14n1p57-76

RESENDE, O. L. Vista cansada. Folha de São Paulo, edição de 23 fev. 1992.

SILVA, S. F. da. Meu encontro com Picasso... e comigo. In: LEITE, M. I.; OSTETTO, L. E. (Orgs.). Museu, educação e cultura: encontros de crianças e professores com a arte. Campinas, SP: Papirus, 2005. p. 157-161.

VECCHI, V. Arte y creatividad en Reggio Emilia; el papel de los talleres y sus possibilidades en educación infantil. Madrid: Ediciones Morata, 2013. 